\title{
Reproductive manipulation in the Whooping Crane Grus americana
}

\author{
E. KUYT
}

\section{Summary}

Whooping Cranes Grus americana increased from 16 wild migratory birds in 1941 to about 146 birds in 1991. Management on the breeding range in Wood Buffalo National Park, Northwest Territories - Alberta, and protection of the birds along their migration route and on the winter range in Texas, are partly responsible for the population increase. The present Wood Buffalo National Park-Aransas National Wildlife Refuge flock consists of almost $50 \%$ non-breeders, mostly subadults. Further increases in the number of breeding pairs beyond the 1991 record of 33 can therefore be expected. The wild population has been a source of surplus eggs, whose removal has not adversely affected population growth. These eggs have been used to establish captive flocks, and captive-reared stock will be used to establish other populations. Attempts to establish a new migratory flock in Idaho by means of cross-fostering Whooping Crane eggs to Sandhill Cranes Grus canadensis have not been completely successful. Present plans call for the establishment of a non-migratory flock in Florida.

\section{Introduction}

It is likely that in North America Whooping Cranes Grus americana were never abundant. Allen (1952) estimated their numbers during the early days of colonization by European settlers to be between 1,300 and 1,400. By 1920 there were probably no more than 50 birds and by 1941 only 22 wild birds remained, six of them non-migratory in a restricted area in Louisiana, where they became extinct by 1948. Illegal hunting and egg-collecting may have contributed to losses of birds but the chief reason may have been the loss of breeding habitat in the marshlands of northern mid-west U.S.A. and prairie Canada. There was little concern about survival of Whooping Cranes until about 1945.

Whooping Cranes are protected under the Migratory Birds Convention of 1916. The Canadian Wildlife Service (CWS) developed and implemented programmes to protect the migratory population which breeds in and near Wood Buffalo National Park (WBNP) and winters on the Aransas National Wildlife Refuge (ANWR) or nearby coastal Texas. The legal mandate for conservation of Whooping Cranes in Canada lies with the CWS but important conservation roles are being played by the Canadian Parks Service, by the provincial governments of Saskatchewan, Manitoba and Alberta and, especially during the early years of conservation programmes, by the Saskatchewan Museum of Natural History and the Saskatchewan Natural History Society.

Cooperative studies and management of Whooping Cranes by the CWS and U.S. Fish and Wildlife Service (USFWS) began in the middle 1960s. In 1985, the 
two agencies signed a Memorandum of Understanding on the conservation of Whooping Cranes to enhance cooperation between them. Each country produced Whooping Crane Recovery Plans (U.S. Fish and Wildlife Service 1986, Canadian Wildlife Service 1988) but these are integrated.

\section{USFWS-CWS project: aims and methods}

The breeding range in WBNP was discovered in 1954 when a Whooping Crane family was observed near the Sass River. At that time the wild population numbered 21 birds. By 1966, this had increased to 44, probably owing to general conservation practices and increased public awareness of the plight of the species.

In 1967, there was a major increase in the level of field studies and management in WBNP, and work at that level has continued until now. Management took account of observations that, although Whooping Cranes normally have clutches of two eggs, wintering birds are rarely accompanied by both young (Erickson 1976). The possibility of increasing the number of cranes by removing one egg from each clutch and rearing it elsewhere gained support. The first transfer of six surplus eggs from WBNP to the Patuxent Wildlife Research Center (PWRC) occurred in 1967.

The objectives of the Whooping Crane programme were: to collect eggs to establish a captive breeding stock; to reintroduce captive-reared progeny to the wild; and to study and manage the WBNP-ANWR Whooping Crane population and its habitats. Reintroduction methods suggested included the release of captive-reared birds at varying ages from enclosures on the breeding range, winter range or along the migration route.

Nests were located and laying dates of eggs determined. One egg or the younger of two hatched chicks was collected from each nest containing two eggs or two chicks. Nests were revisited to determine if adult birds had returned and to collect the second egg if a nest had been abandoned. Eggs were transferred to Fort Smith and a 24-hour watch was maintained over the eggs until shipment to the U.S.A.

Between 1954 and 1967 , aerial surveys were conducted over parts of the Sass River breeding range (Novakowski 1966). In 1967, I extended surveys into the Klewi River area where several nests were found. Since then, other nest locations, separate from Sass and Klewi, have been discovered. Before 1966 aerial surveys had been carried out in small helicopters, but thereafter most flights have used small fixed-wing aircraft because of lower charter costs, greater range and less disturbance to birds.

An outline of the cranes' annual cycle and the fieldwork that tracked it from 1967 to 1991 is as follows. Spring migration from ANWR begins in late March to early April, and all birds have usually left the refuge by the end of April. The first migrants, generally family groups (two adults and their juvenile of the previous year) and other experienced breeding pairs, begin arriving at the breeding area in WBNP during the last week in April. Aerial surveys enable us to plot locations of birds on aerial photographs and the beginning of nesting is recorded. By mid-May laying activities are generally at an end.

Surplus eggs are removed annually by helicopter before the end of May. The viability of each egg left in every nest is assessed to ensure that a live egg is 
present. Eggs are transported to their destination in the U.S.A. as soon as possible after collection.

During July, paired adults and their young are located by aerial surveys and identified by their nest site; the movements of these family groups are monitored for the rest of the season. In most cases, the identity of family groups can be ascertained by colour-banded individuals (about $64 \%$ of 33 breeding pairs in 1991) or location.

In early August flightless juveniles are captured, measured and colourbanded. During colour-banding of juveniles in 1980, 1982, 1984, 1985 and 1986, small blood samples were collected for sex determination. Colour-banding was terminated after the 1988 season and will not be renewed unless a special need should occur. About $46 \%$ of the 1991 WBNP population of 146 cranes are colour-banded and data collection will continue for several more years.

Between 1981 and 1984, nine juvenile and subadult Whooping Cranes were radio-tracked from light aircraft flying from WBNP to ANWR in fall, and from the winter range to WBNP in spring. In most cases, trackers were able to maintain visual contact with the radio-equipped cranes and their parents, sometimes for as much as one-half of the $4,000 \mathrm{~km}$ migration. Information was obtained about the cranes' migration corridor, migratory behaviour, locations and use of stopover sites, mortality factors and other details.

As the number of breeding pairs of Whooping Cranes in the WBNP flock increases, the number of non-breeding birds also increases. Currently there may be as many as 76 non-breeders, most of which are subadults $1-3$ years of age. Although summer locations of all non-breeders are unknown, many are seen during spring counts and aerial searches for family groups in summer.

Most birds can be identified to age, origin and sometimes sex. Each year paired subadults are located, and these observations sometimes extend the known breeding range. Many of these pairs may eventually nest in the areas where they were first observed.

\section{Work in Wood Buffalo National Park}

Since 1967 there has been a high correlation between number of nests found in WBNP and number of families with young arriving in ANWR. Only an occasional nest or nesting pair has remained undetected since that time. Most of the 33 or so nesting pairs occupy a total area of $500 \mathrm{~km}^{2}$, just over $1 \%$ of the $45,000 \mathrm{~km}^{2}$ embraced by WBNP. Most of the non-breeding birds summer there also. Although total summer population counts are not attempted, up to $84 \%$ of the total annual population has been sighted in or near the core $500 \mathrm{~km}^{2}$ area.

About five aerial surveys of 3-5 hours duration were usually flown at a $700-$ $800 \mathrm{~m}$ altitude. Each nesting area was searched until a nest (indicated by an adult on the nest) was found. The aircraft descended until the bird on the nest rose, revealing its egg(s). If the two-egg clutch was complete (incidence of two-egg clutches is over 90\%: Kuyt 1987), the birds were no longer approached. They were occasionally checked thereafter from a high altitude to ensure cranes were still attending the nest.

If a nest contained one egg, a second visit was made two days later when the clutch was expected to be complete. Laying dates were thus determined. 
Eggs were collected about 24 days into the 29/30-day incubation period. Eggs are laid one day apart and incubation (shared by both parents) begins with the first egg. Between 1985 and 1991, 66-92\% of eggs were laid between 26 April and 12 May.

All previously occupied nesting areas are visited. By the end of the spring surveys we have a register of nest sites and egg-laying dates. Information obtained from ANWR (where breeding pairs and family groups have winter territories) provides an indication of which breeding pairs have suffered mortality and which subadults are consorting with other cranes and could be expected to form new breeding pairs. New pairs are often found breeding for the first time in areas occupied as subadults, particularly as three-year-old birds. Almost all potential novice breeding pairs are located during spring surveys.

Nine nesting pairs were found in 1967 in WBNP. Increased coverage of the potential breeding range from 1967 to 1972 resulted in the location of up to 16 nests. Surveys of the same area indicated an increase to 24 nesting pairs in 1983, 28-32 nesting pairs (1984-1990) with a record of 33 nests established in 1991. Information on egg viability in the field cannot be obtained from eggs younger than 12 days. Collection of these eggs was avoided. Egg-collectors walked to the nest site through water as much as possible to minimize tracks which could attract predators (black bear Ursus americanus and grey wolf Canis lupus). The nest was measured, and water depth, nest material and habitat recorded. Eggs were examined and abnormal eggs (irregular shape, cold; putrid odour) removed. Each normal egg was placed in a container of water at 30$35^{\circ} \mathrm{C}$, and the position of the egg in the water noted to determine incubation stage. If both eggs appeared normal, the egg removed was picked at random. No nest was abandoned as a result of human interference.

Novice breeding pairs nested later than experienced breeders and were less successful. Of 18 pairs nesting for the first time from 1986 to 1991 at least four had single-egg clutches and both eggs in three other pairs' two-egg clutches were non-viable. Two novice pairs' eggs were destroyed by an unknown predator and although five of the 18 novice pairs raised single chicks, only two raised their own, while the other three pairs raised chicks from substituted eggs.

Eggs removed are given a catalogue number (written on the egg with a soft lead pencil) and placed in a portable incubator. At Fort Smith they are transferred to a thermostatically controlled incubator which maintains an internal temperature of $37.0-37.4^{\circ} \mathrm{C}$. Correct humidity is maintained by water in the incubator below a screen on which the eggs rest. All eggs are weighed, measured and floated to re-check viability just prior to shipment to the U.S.A., and again on arrival there. Hatching success has been high, reaching $78-100 \%$ for 50 eggs shipped to Patuxent between 1967 and 1974 (Erickson 1976) and $77 \%$ of 166 eggs shipped to Grays Lake between 1975 and 1988 (R. C. Drewien pers. comm.). Between 1967 and 1991 a total of 355 eggs has been shipped successfully to incubation centres.

In 1985 , aided by greater familiarity with viability testing techniques, CWS began regularly substituting known live eggs into nests of pairs with 
consistently low hatching success. For example, on 4 May 1987, two birds were seen near an empty nest in the Sass River area. On 7 May, there was one egg in the nest. Three days later, the nest was empty although a bird continued to incubate. After 11 days, an egg, several days from hatching, was placed in the empty nest. The adults accepted the egg. The resulting chick was banded about three months later and subsequently recorded during aerial surveys in 1988 and 1989.

From 1939 to 1966 and in 1970, 1972 and 1973, when eggs were not collected in WBNP, 4.3 young were produced annually. From 1967 to 1969, in 1971 and in 1974, when surplus eggs were collected annually, an average of 6.0 young were produced each year by up to 16 breeding pairs.

An analysis of the hatching success of tested and untested eggs between 1985 and 1988 shows that a minimum of $83.1 \%$ of tested (viable) single eggs left in 83 nests during this period hatched, and that during the same period 25 untested eggs (67.6-71.4\%) hatched from a minimum of 35-37 untested eggs. Hatching success increased from $11.7 \%$ to $15.5 \%$. Between 1985 and 1991, 19.1 young were produced annually. From 1967 to 1990 the WBNP-ANWR population increased from about 48 to 146 birds.

\section{Captive breeding}

The U.S. Endangered Wildlife Research Program was established in 1965 in permanent facilities at PWRC. Its main objectives (Erickson 1968) were to obtain information from threatened species in the wild, identify and evaluate limiting factors, and maintain captive populations of these species for study, propagation and eventual reintroduction into the wild.

The first Whooping Crane in Patuxent was an injured, juvenile male caught in WBNP in 1964. This bird, 27 years old in 1991, has acted as a donor for artificial insemination. By summer 1991 there were approximately 39 captive Whooping Cranes at PWRC, 28 at the International Crane Foundation (ICF) in Wisconsin and two elsewhere.

Whooping Cranes have proved to be more difficult to raise in captivity than Sandhill Cranes Grus canadensis, and downy young have suffered high mortality (68.3\%: Derrickson and Carpenter 1981). Infectious disease (31.7\%), parasitic disease (19.5\%), and anatomical abnormalities (19.5\%) caused the highest mortality of captive Whooping Cranes at Patuxent between 1966 and 1981 (Carpenter and Derrickson 1981). In fall 1984, seven birds, including a breeding female, died of eastern equine encephalitis, a virus spread by an uncommon species of mosquito (Culiseta melanura). In 1987, three cranes died of a food-related illness.

Since 1955, single or paired Whooping Cranes have been kept at the Audubon Park Zoo, New Orleans, and San Antonio Zoo, Texas. Although down to 1991 at least 75 eggs had been produced and a few young reached adulthood, most reproductive efforts resulted in infertile or abnormal eggs.

Captives first bred at Patuxent in 1975 when a seven-year-old female laid three eggs. Since then, the youngest female to lay was a five-year-old (Derrickson and Carpenter 1981). Successful breeding by wild birds at three or four years of age 
has also been recorded (Kuyt and Goossen 1987). In 1984, five captive females produced 31 eggs, and in 1989 five females produced 19 eggs of which nine hatched.

Since 1984,13 adults (mostly of breeding age) and subadults have died from disease at PWRC. To eliminate the risk that all captive birds might be killed by a single disease outbreak, a proposal was made in 1988 to divide the captive flock at PWRC and move some to ICF. Twenty-two cranes were shipped to ICF later in 1989 to join the two already there.

\section{Cross-fostering experiment}

In 1975 the USFWS and CWS initiated a cooperative experiment to reintroduce Whooping Cranes in the Rocky Mountain region of the United States. Reintroduction techniques involved placing surplus eggs from WBNP into preselected nests of Greater Sandhill Cranes G. c. tabida at Grays Lake National Wildlife Refuge (GLNWR) in south-east Idaho (Drewien and Bizeau 1978, Drewien and Lewis 1983). Introductions of WBNP eggs were made annually from 1975 to 1988. From 1976 to 1984 (except 1981) Patuxent-produced eggs were also transferred to GLNWR.

The Grays Lake area was selected for the experiment after completion of studies which showed that the high-density Sandhill Crane population there maintained a high nesting success (78-92\%) and had a nesting chronology similar to that of WBNP (R. C. Drewien pers. comm.). Additional factors also indicated that the experiment had a reasonable chance of success (Drewien and Bizeau 1978).

Almost $73 \%$ (i.e. 210) of introduced Whooping Crane eggs (215 eggs from WBNP, 73 eggs from PWRC) hatched at GLNWR; the hatching success of Canadian eggs $(77 \%)$ exceeded that of the eggs from PWRC (60\%). Fifteen of the 215 WBNP eggs did not contain detectable embryos or were infertile. Most of these non-viable eggs were transferred in earlier years before diagnostic viability tests were conducted.

Primary causes of $78 \mathrm{egg}$ failures at GLNWR included predation (chiefly by coyotes Canis latrans), infertility or embryonic death, particularly in 1981 and 1982 (R. C. Drewien pers. comm.). Most chick mortality (47 cases) occurred before the birds were 30 days old. Predation (coyotes and red fox Vulpes vulpes) and bad weather (late snow storms, rain and low temperature) were chief mortality factors of young Whooping Cranes. Drought, accompanied by low water levels in Grays Lake, reduced food supplies and caused young cranes to starve in several years. Poor physical condition of surviving young cranes probably predisposed birds to mortality during their first migration.

Of 85 Whooping Cranes fledged at GLNWR since 1975, only 13 were still alive in the summer of 1991 (R. C. Drewien pers. comm.). Mortality factors are known for $27(37.5 \%)$ of the other 72 . The greatest proportion of known fatalities was caused by powerline collisions (40\%), especially in Colorado, followed by contact with fences $(22 \%)$, disease $(18 \%)$ and avian predation $(7 \%)$. Survival rates of females (except yearlings) were lower than those of males (R. C. Drewien pers. comm.).

Whooping Cranes from Grays Lake feed mainly on barley and wheat during 
fall and spring in Colorado, and on corn during winter in the Rio Grande valley, New Mexico. There are few wetlands suitable for roosting and feeding in the Rio Grande valley. Food shortages, and increasing numbers of Lesser Snow Geese Chen caerulescens and Sandhill Cranes (and consequent disturbance of Whooping Cranes by hunters), have resulted in erratic movements by Whooping Cranes including premature spring migrations from New Mexico, and movements of some cranes south into Mexico.

No permanent pairs have yet been formed among Grays Lake Whooping Cranes. Possible causes are that a few cranes are spread over a rather large geographic area; there are few older females in the population; females do not return to Grays Lake or meet with unpaired males; or Whooping Cranes raised by Sandhill Cranes are imperfectly imprinted (R. C. Drewien pers. comm.).

To enhance opportunities for pair formation at GLNWR, 13 translocations involving nine different birds were carried out from 1986 to 1988 . None of the birds strayed far from the Grays Lake release site but only one female (a three-year-old, in 1989) returned to Grays Lake in subsequent years.

\section{Establishment of non-migratory flock}

When it appeared that the Grays Lake experiment would not meet with complete success, the Whooping Crane Recovery Teams of the U.S.A. and Canada approved a project to establish a non-migratory flock of Whooping Cranes in Florida, with the first introduction (five captive-raised, radio-equipped birds) scheduled for early 1992 with a health-check recapture after 12 months. Further introductions will depend on survival and mortality factors. The introduction of non-migratory Whooping Cranes in Florida is a preliminary step towards the establishment of a second migratory flock. Planning for such a flock is under way.

\section{Conclusions}

The WBNP-ANWR Whooping Crane flock is the world's only viable population. It is of the utmost importance that present management and protection of this wild population continue, not only on its summer and winter range but also in its migration habitat.

A viable and increasing wild population will also serve as a reservoir for surplus eggs to be used in the establishment of other wild flocks, should locations and methods of reintroduction be acceptable. When techniques of captive breeding and raising of Whooping Cranes are perfected, cranes so reared may eventually also be used to augment wild populations.

At all times, risks to the original, wild population should be avoided, including risks of disease contamination from captive-produced stock.

\section{Acknowledgements}

Allen's (1952) monograph continues to be a great contribution to our understanding of Whooping Crane ecology. Close cooperation between CWS and the USFWS (particularly the Patuxent Wildlife Research Center), University 
of Idaho and Canadian Parks Service has existed for a long time. Other organizations such as the Government of the Northwest Territories, the Whooping Crane Conservation Association Inc., the International Crane Foundation and the National Audubon Society continue to play important supportive roles.

\section{References}

Allen, R. P. (1952) The Whooping Crane. New York: National Audubon Society Research Report 3.

Canadian Wildlife Service (1988) Canadian Whooping Crane recovery plan. Environment Canada catalogue no. CW66-91/1988E.

Carpenter, J. W. and Derrickson, S. R. (1981) Whooping Crane mortality at the Patuxent Wildlife Research Center 1966-1981. Pp.175-179 in J. C. Lewis, ed. Proceedings 1981 Crane Workshop. Tavernier, Florida: National Audubon Society.

Derrickson, S. R. and Carpenter, J. W. (1981) Whooping Crane production at the Patuxent Wildlife Research Center, 1967-1981. Pp.190-198 in J. C. Lewis, ed. Proceedings 1981 Crane Workshop. Tavernier, Florida: National Audubon Society.

Drewien, R. C. and Bizeau, E. G. (1978) Cross-fostering Whooping Cranes to Sandhill Crane foster parents. Pp.201-222 in S. A. Temple, ed. Endangered birds: management techniques for preserving threatened species. Madison, Wisconsin: University of Wisconsin Press.

Drewien, R. C. and Lewis, J. C. (1983) Status and distribution of cranes in North America. Pp.469-477 in G. W. Archibald and R. F. Pasquier, eds. Proceedings 1983 International Crane Workshop. Baraboo, Wisconsin: International Crane Foundation.

Erickson, R. C. (1968) A federal research program for endangered wildlife. Trans. 33 North American Wildl. and Nat. Res. Conf.: 418-433.

Erickson, R. C. (1976) Whooping crane studies at the Patuxent Wildlife Research Center. Pp.166-176 in J. C. Lewis, ed. Proceedings of the International Crane Workshop. Stillwater: Oklahoma State University.

Kuyt, E. (1987) Management and research of Whooping Cranes, 1965-1982. Pp.365-370 in G. W. Archibald and R. F. Pasquier, eds. Proceedings 1983 International Crane Workshop. Baraboo, Wisconsin: International Crane Foundation.

Kuyt, E. and Goossen, J. P. (1987) Survival, age composition, sex ratio, and age at first breeding of Whooping Cranes in Wood Buffalo National Park, Canada. Pp.230-244 in J. C. Lewis, ed. Proceedings 1985 Crane Workshop. Grand Island, Nebraska.

Novakowski, N. S. (1966) Whooping Crane population dynamics on the nesting grounds, Wood Buffalo National Park, Northwest Territories. Canadian Wildlife Service Report Series No. 1.

U. S. Fish and Wildlife Service (1986) Whooping Crane Recovery Plan. Albuquerque, New Mexico: U. S. Fish and Wildlife Service.

\section{E. KUYT}

Canadian Wildife Service, Environment Canada, 4999 - 98 Avenue, Edmonton, Alberta T6B $2 X_{3}$, Canada. Current address: $3810-103$ B. Street NW, Edmonton, Alberta T6J $2 X_{9}$, Canada. 